\title{
Young children's sensitivity to new and given information when answering predicate-focus questions
}

\author{
DOROTHÉ SALOMO, ELENA LIEVEN, and MICHAEL TOMASELLO \\ Max Planck Institute for Evolutionary Anthropology
}

Received: February 22, 2008 Accepted for publication: March 21, 2009

\author{
ADDRESS FOR CORRESPONDENCE \\ Dorothé Salomo, Max Planck Institute for Psycholinguistics, Wundtlaan 1,6525 XD, Nijmegen, \\ The Netherlands. E-mail: dorothé.salomo@mpi.nl
}

\begin{abstract}
In two studies we investigated 2-year-old children's answers to predicate-focus questions depending on the preceding context. Children were presented with a successive series of short video clips showing transitive actions (e.g., frog washing duck) in which either the action (action-new) or the patient (patient-new) was the changing, and therefore new, element. During the last scene the experimenter asked the question (e.g., "What's the frog doing now?"). We found that children expressed the action and the patient in the patient-new condition but expressed only the action in the action-new condition. These results show that children are sensitive to both the predicate-focus question and newness in context. A further finding was that children expressed new patients in their answers more often when there was a verbal context prior to the questions than when there was not.
\end{abstract}

Questions make up approximately one-third of mothers' speech to their young children (Cameron-Faulkner, Lieven, \& Tomasello, 2003). Children's answers to questions have been examined almost exclusively with respect to syntactic and semantic aspects of question-answer pairs (e.g., Ervin-Tripp, 1970; Peterson \& Biggs, 1997; Tyack \& Ingram, 1977). However, an answer is expected above all to be informative for the questioner, that is, to provide the questioner with information that is new, rather than with information that is already given (Kiefer, 1988). What is given information is partly determined by the wording of the question; that is, information that is already mentioned in the question is assumed to be known to the questioner (Lambrecht, 1994). However, in addition, the context in which a question is uttered often also provides given information in addition to that which is included in the question itself (Kiefer, 1988). This context can be either verbal or visual: information can have been mentioned already and/or can be available in the context and the visual focus of attention. In either case it can be considered as "given" (Chafe, 1976). That is, when an element is given in the preceding context (i.e., prior to the question) there is no need to present it as new information (e.g., in a lexical noun) in the answer, even when it constitutes part of the requested

(C) Cambridge University Press 2009 0142-7164/10 \$15.00 
information. Instead, it may be either omitted or marked as given, for example, by using a pronoun.

Giving an appropriate answer to a question while taking the preceding context into account requires a twofold effort: (a) one needs to pay attention to the question and determine what information is already given and what information is requested, and (b) one needs to judge with respect to the preceding context what part of the requested information is already given and tailor the answer accordingly. Because questions narrowly focus on the information required, they are an interesting topic for understanding how children coordinate given and new information within and between utterances in discourse. One might expect this to be a more difficult task than simply following the preceding utterance of an interlocutor in a discourse-coherent way. There is also the question of whether prior mention in discourse makes it easier or more difficult to identify given information by contrast with the information being presented only visually.

Previous research has shown that children as young as 2 years are very sensitive to the preceding discourse in general, that is, they express elements that have not been mentioned yet, and which are thus new information in discourse, in an informative way, and elements that have been mentioned before, noninformatively (e.g., Allen, 2000; Clancy, 1997; Narasimhan, Budwig, \& Murty, 2005; Serratrice, 2005). With respect to question answering, it has been shown that 2-year-old children's choice of referring expressions in answers to questions is strongly influenced by whether a particular referent was already mentioned in the question or not (Campbell, Brooks, \& Tomasello, 2000; Wittek \& Tomasello, 2005). However, to our knowledge, the issue of whether the preceding discourse context prior to a question influences children's answers has only been examined in one study so far. Matthews, Lieven, Theakston, and Tomaello (2006) investigated children's referring expressions in answers to questions depending on whether or not a certain character has been mentioned in the preceding discourse context prior to the question. Children watched video clips (e.g., a clown jumping) and were asked a sentence-focus question ("What happened?"). This type of question requires the answer to encode the whole event (Salomo, Lieven, \& Tomasello, 2009; cf. Lambrecht, 1994), such as "The clown is dancing." Matthews et al. (2006) concentrated on nominal expressions, and varied in two conditions whether or not the questioner mentioned the performing character (i.e., the clown) prior to the question. More precisely, in one condition the experimenter asked the child "That sounds like fun! What happened?", whereas in the other condition the experimenter overheard the name of the character involved and remarked: "Was that the clown? Oh! What happened?" When the character has been mentioned in the preceding discourse context, it is not necessary to express it informatively (i.e., in a lexical noun) in the answer, but rather it can be expressed as a pronoun.

Matthews et al. (2006) found that 3- and 4-year-old children replied with a lexical noun and a verb (e.g., "The clown is dancing") when the experimenter had not yet mentioned the name, but they gave a pronoun and verb response (e.g., "He is dancing") when the character had been named before. Even children as young as 2 years of age adapted their responses according to whether or not there had 
been prior mention of a noun by the questioner, specifically by varying their use of nouns as opposed to verbs. Thus, the referring expression used often appeared to be the outcome of deciding whether to comment on the character or the action that was performed: when there was no prior mention of the character, 2-yearolds were more likely to simply name it (e.g., "clown"), but when the character had been previously mentioned, children omitted that argument more often and reference to the character's action became more likely (e.g., "dancing"). Thus, although 2-year-old children showed sensitivity to the interlocutor's question with respect to the actor of the event, they appeared to not consider the interlocutor's knowledge state with respect to the character's action.

In the current study we examined children's expression of verb phrases (i.e., verb and patient) in their answers to questions depending on the preceding discourse context; that is, we focused not only on expressions referring to nominals, but we also analyzed children's reference to actions. One possible reason for the young children's performance in Matthews et al.'s (2006) study might be that What happened? questions are difficult for young children to answer, mainly because it is not clear to the child what exactly is being asked for. There is also the possibility that in the absence of a clear question focus, nominals are easier to access than verbs, given the suggestion that English-speaking children represent the category of nouns earlier than that of verbs (e.g., Gentner, 1982). In our study, therefore, we used a question type that has been shown to be easier for 2-year-old children to answer (Salomo et al., 2009): a predicate-focus question (What's $X$ doing?). Predicate-focus questions ask directly for an action, and if this action is a transitive one (as in the current study), the patient is also required for the answer to be fully informative.

There were two conditions in which the question we asked was identical, whereas the givenness/newness of the action and the patient were manipulated prior to the question. In one condition, the action was discourse-new, because children watched a series of video clips prior to the question in which the same participants (agent and patient) were involved in different activities successively (action-new condition). In the other condition, the patient was discourse-new, because an agent did the same action successively to different patients (patientnew condition). During the last scene children were asked "What's AGENT doing now?"

We expected children to express the patient in their answers in the same way as in Matthews et al.'s (2006) study, that is, by using lexical nouns when the patient was the new element (patient-new condition), and by using pronouns or null references when the patient was given (action-new condition). However, because our question focused on an action, we, in addition, expected the children to include the verb in their answers in most cases. However, the verb might occur less often when it corresponds to the given element (patient-new condition) than when it is the new element (action-new condition). In Study 1 the manipulation of the newness/givenness of the elements was done visually (using video clips) and orally (with accompanying utterances). In Study 2 only the visual information was provided to compare the difference that the provision of a verbal discourse context for given information made to the children's expression of given and new information in their answers. 
Salomo et al.: Answering predicate-focus questions

\section{STUDY 1}

\section{Method}

Participants. Sixteen ( 7 boys, 9 girls) monolingual 2 -year-old $(M=2$ years, 3 months, 28 days $[2 ; 3 ; 28]$, range $=2 ; 3 ; 00-2 ; 4 ; 21$ ) German-speaking children were included in the study. A further three children participated but were excluded from analysis because they either did not complete the session (two), or they did not meet the criterion of providing at least one answer per condition (one). The children were tested in a quiet area in their nursery in a middle-size German city.

Materials and design. Short video clips were created that show transitive actions acted out by toy animals. In a pilot test, we made sure that 2-year-old children were able to name the actions and the animals. Each video clip consisted of a sequence of three scenes in which one and the same agent performed transitive actions on patients. In this sequence of events, all elements remained constant but one. There were two conditions: (a) action-new condition: an agent did three different actions to one patient (e.g., frog feeding duck, frog combing duck, frog washing duck); and (b) patient-new condition: an agent did the same action to three different patients (e.g., frog washing ladybug, frog washing hedgehog, frog washing duck). Consequently, one and the same target scene (e.g., frog washing duck) had two different types of context scenes, depending on whether it occurred in the action-new or in the patient-new condition. There were four different target scenes, which were the same for all children: frog washing duck, monkey pushing mouse, frog hitting teddy, monkey stroking lion. Children were asked a predicatefocus question during the target scenes: "Was macht denn AGENT jetzt?" ("What's AGENT doing now?"). The study employed a within-subject design, and children were tested in both conditions twice, resulting in four test questions per child corresponding to the four different target scenes, two in each condition. The order of the target scenes as well as the order of conditions (half of the children got the action-new condition first and the other half started with the patient-new condition) was counterbalanced. A list of all video clips can be found in Appendix A. A 12-in. Macintosh iBook was used to play the video clips using Quick Time Player ${ }^{\circledR}$.

Procedure. The study took place in a quiet room in the child's nursery. Before the experiment started, the experimenter played a marble game with the child until the child seemed comfortable with the situation. For the experiment, the child and the experimenter sat together in front of a notebook where the video clips were shown in full screen mode. Before playing the videos, the experimenter explained that they were going to watch a video about a frog/a monkey. During the first two scenes of each trial, the experimenter described the scenes. Thus, when the first scene starts, the experimenter said for a given scene/condition: "Kuck mal! Der Frosch wäscht den Marienkäfer. Oh! Der Frosch wäscht den Marienkäfer. Das ist ja lustig." ("Oh, look! The frog is washing the ladybug. Oh! The frog is washing the ladybug. That's fun, isn't it?"), describing each scene twice. When the second scene appeared, the experimenter said similarly: "Kuck mal jetzt! Der Frosch wäscht den Igel. Oh! Der Frosch wäscht den Igel. Na, sowas!" ("Look now! The frog is washing the hedgehog. Oh! The frog is washing the hedgehog. Oh wow!"). 
Salomo et al.: Answering predicate-focus questions

Table 1. Mean percentage of use of different response types for the two conditions in Study 1

\begin{tabular}{lccc}
\hline \hline Condition & Action Only & Patient Only & Action + Patient \\
\hline Action new & 75.0 & 3.1 & 21.9 \\
Patient new & 9.4 & 31.3 & 59.4 \\
\hline \hline
\end{tabular}

Note that the experimenter used natural stress when describing the scenes. When the third scene started, the experimenter asked the test question "Oh! Was macht denn der Frosch jetzt?" (“Oh! What's the frog doing now?"). When asking the question the experimenter looked a bit puzzled, pretending not to recognize what was going on in the film. This was done so as not to make the child feel that she was being tested, but rather that the experimenter truly needed the child's help in finding out what was happening. In case the child did not answer, the experimenter would repeat the question for a maximum of three times while the video was still running.

The two trials per condition came in one block followed by a short break (playing the marble game again) followed by the two trials in the other condition.

Coding. We coded the children's responses for two aspects: (a) what is expressed in the answer: action only (e.g., washing), patient only (e.g., duck), or action and patient (e.g., washing the duck or washing it); and (b) how the patient is expressed: lexical noun (e.g., duck), pronoun (e.g., it), or null reference. ${ }^{1}$ Unintelligible utterances (1), question repetitions (1), and cases where no response was given at all (2) were excluded from the analysis. Therefore, our results are based on 60 answers (30 in the action-new condition, 30 in the patient-new condition). To assess interobserver reliability, a random sample of 4 out of the 16 subjects $(25 \%)$ was scored by a second coder. This observer agreed with the primary coder's judgment in $100 \%$ of the trials.

\section{Results}

Our main interest was the children's realization of the action word and patient in their answers to the predicate-focus question. Therefore, in our analysis we focused on these two elements. ${ }^{2}$ An overview of the distribution of the children's response types can be seen from Table 1. For each of these types we conducted pairedsamples $t$ tests. These revealed that children made more action-only responses in the action-new condition, $t(15)=6.619, p<.001$, more patient-only responses in the patient-new condition, $t(15)=-2.764, p<.05$, and more action + patient responses in the patient-new condition, $t(15)=-3.503, p<.01$. Thus, children used more multiword utterances in answering questions in the patient-new condition than in the action-new condition.

Adding together columns 1 and 3 as well as columns 2 and 3 in Table 1, we found that children expressed overall the action more often in the action-new condition than in the patient-new condition, $t(15)=2.764, p<.05$, paired-samples $t$ test, 


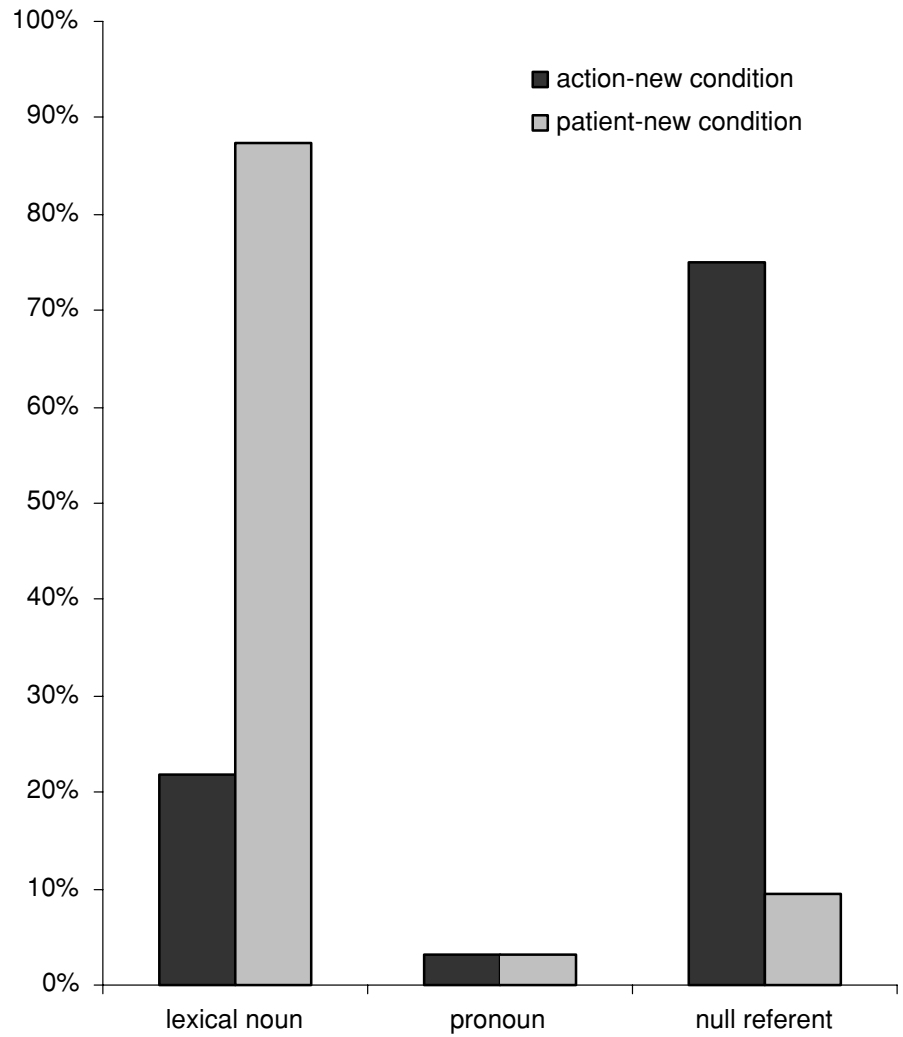

Figure 1. The mean percentage of use of different referring expressions for both conditions in Study 1.

and the patient more often in the patient-new condition than in the action-new condition, $t(15)=-6.619, p<.001$, paired-samples $t$ test.

In a further analysis we looked at children's patient expressions in more detail (see Figure 1). Paired-samples $t$ tests were performed for each of the patient types (except pronoun responses, which were too infrequent). As noted above, null references occurred very frequently in the action-new condition $(75.0 \%)$, whereas they were rare in the patient-new condition $(9.4 \%), t(15)=6.619, p<.001$. However, lexical nouns were used significantly more often in the patient-new condition $(87.5 \%)$ than in the action-new condition $(21.9 \%), t(15)=-6.012$, $p<.001$. Thus, children realized the patient as a lexical noun more often in the patient-new condition and used more null references for the patient in the action-new condition.

To summarize, when the action was the new element in the series of succeeding scenes, children were very likely to respond to the question with a one-word utterance, which was a single verb. However, when the patient was the new 
element, children used many more multiword utterances when answering the question: they expressed the patient typically as a lexical noun in their answers and in addition, they included the verb very often, even though less often than in the action-new condition.

\section{Discussion}

In Study 1 we examined how young 2-year-old children answered predicatefocus questions depending on the preceding context in which we manipulated the newness/givenness in discourse of either the action or the patient of that action. We found that children expressed the action and the patient in the patient-new condition but expressed only the action in the action-new condition. These results show that children are very sensitive to both the question and givenness/newness in the preceding discourse context.

There were two factors in our study that were relevant for children's answers: (a) predicate-focus question, thst is, a question that strongly pulls for a verb answer; and (b) newness, which corresponds to the action in the action-new condition and to the patient in the patient-new condition. These two factors aim for one and the same element (i.e., the action) in the action-new condition: whereas in the patientnew condition the newness aims for the patient, while the question aims primarily for the action. This is exactly what we found in the children's answers: when the action was the new element in the preceding context, children mostly answered the predicate-focus question with a one-word utterance, namely, a verb. However, when the patient was the new element in the preceding context, children would answer exactly the same question with a verb and a lexical noun for expressing the patient.

Thus, when young children are provided with a verbal discourse context and a predicate-focused question, they seem to have little difficulty in identifying the information that the question asks for and the information that is new from the preceding discourse.

In this study the context for given information was established in discourse. How much difference would it make if this information was simply presented contrastively in the videos but not verbally expressed? To examine whether the results were influenced by the experimenter's verbal description of the context scene preceding the question, we conducted a further study. The procedure was basically the same, with the exception that the experimenter did not verbally describe the context scenes.

\section{STUDY 2}

\section{Method}

Participants. Sixteen ( 9 boys, 7 girls) monolingual young 2 -year-old $(M=2 ; 3 ; 22$, range $=2 ; 3 ; 03-2 ; 4 ; 24$ ) German-speaking children were included in this study. A further three children were excluded from analysis because they did not meet the criterion of giving at least one answer per condition. There was no overlap in the children who participated in the two studies. 
Salomo et al.: Answering predicate-focus questions

Table 2. Mean percentage of use of different response types for the two conditions in Study 2

\begin{tabular}{lccc}
\hline \hline Condition & Action Only & Patient Only & Action + Patient \\
\hline Action new & 78.1 & 6.3 & 15.6 \\
Patient new & 36.7 & 23.3 & 40.0 \\
\hline \hline
\end{tabular}

Materials and design. The materials and design were the same as in Study 1.

Procedure and coding. The procedure of this study was the same as in Study 1 with the exception that the experimenter did not describe the first two scenes for the child, that is to say, while watching the clips, E said only things such as "Das ist ja toll!" ("That's great."), "Das ist ja lustig, oder?" ("That's fun, isn't it?") to keep the child's attention and interest. As the third scene started, E asked the child (as in Study 1): "Oh! Was macht denn der Frosch jetzt?" ("Oh! What's the frog doing now?").

Coding was the same as in Study 1. Unintelligible utterances (2), question repetitions (1), and cases where no response was given at all (9) were excluded from the analysis. Therefore, our results are based on 52 answers (26 in the actionnew condition, 26 in the patient-new condition). To assess interobserver reliability, a random sample of 4 out of the 16 subjects (25\%) was scored by a second coder who agreed with the original coder in $93.8 \%$ (Cohen $\kappa=.897$ ).

\section{Results}

An overview of the distribution of the children's response types can be seen in Table 2. For each of these types we conducted paired-samples $t$ tests. Those revealed that, as in Study 1, children made significantly more action-only responses in the action-new condition, $t(14)=3.055, p<.01$. Furthermore, a tendency for more patient-only responses in the patient-new condition was found, $t(14)=$ $-1.784, p=.096$, as well as a tendency for more action + patient responses in the patient-new condition, $t(14)=-1.974, p=.068$.

Adding together columns 1 and 3 as well as columns 2 and 3 in Table 2, we found that, as in Study 1, children expressed the patient more often in the patient-new condition than in the action-new condition, $t(14)=-3.055, p<$ .01 , paired-samples $t$ test). However, contrary to what we have found in Study 1, children expressed the action equally often in both conditions (paired-samples $t$ test, $n s)$.

In a further analysis we looked at children's patient expressions in more detail (see Figure 2). Paired-samples $t$ tests were performed for each of the patient types (except pronoun responses, which were too infrequent). Null references occurred very frequently in the action-new condition $(78.1 \%)$, whereas they were less frequent in the patient-new condition $(46.9 \%), t(15)=2.611, p<.05$. Lexical nouns were used $53.1 \%$ in the patient-new condition, but only $18.8 \%$ in the actionnew condition, $t(15)=-2.905, p<.05$. Thus, as in Study 1 , children dropped the 


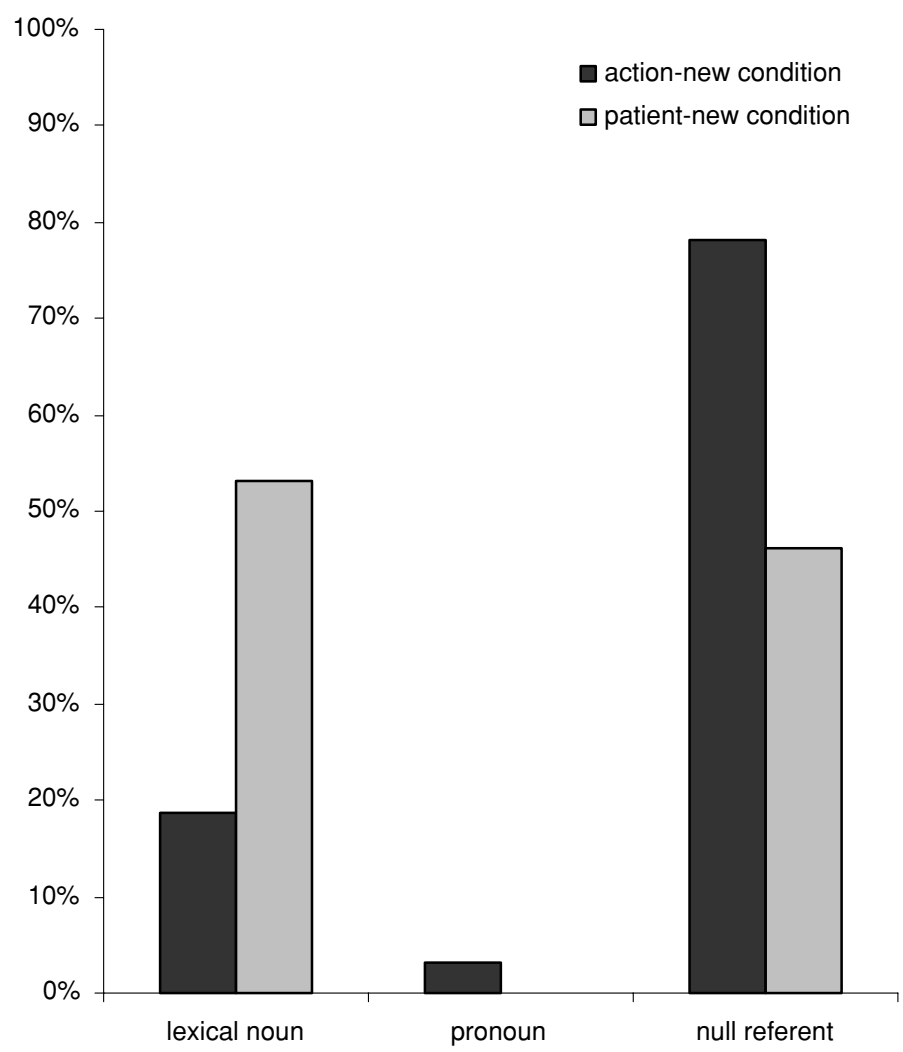

Figure 2. The mean percentage of use of different referring expressions for both conditions in Study 2 .

patient more often when it was the given element (action-new condition), and they expressed it more often as a lexical noun phrase when it was new (patient-new condition).

Comparison of Study 1 and Study 2. To analyze the effect of the absence versus presence of the verbal description of the videos to children's answers, we compared children's answers in Study 1 and Study 2 with respect to (a) response types, (b) overall expression of action and of patient, and (c) patient type.

For each the response types, a 2 (Study) $\times 2$ (Condition) analysis of variance (ANOVA) was performed with the mean proportion of response type as the dependent variable. Neither a main effect for study nor an interaction for study and condition was found for any of the three response types (action-only, patient-only, action + patient). ${ }^{3}$ With respect to the overall expression of action and patient, a 2 (Study) $\times 2$ (Condition) ANOVA was performed for each of them with the mean proportion of actions and patients as the dependent measure, respectively. Again, 
neither a main effect for study nor an interaction for study and condition was found for either of them. Finally, for the realization of the patient, a 2 (Study) $\times 2$ (Condition) ANOVA was performed for each of the patient types (except for pronouns, which were too infrequent) with the mean proportion of patient type as the dependent variable. The ANOVA on patients that were expressed as lexical noun phrases revealed a marginally significant main effect for study, $F(1,30)=3.518$; $p=.070$, as well as a marginally significant interaction for study and condition, $F(1,30)=3.769 ; p=.062$. The ANOVA on patients that were null referents revealed a marginally significant main effect for study, $F(1,30)=4.017 ; p=$ .054 , as well as a significant interaction for study and condition, $F(1,30)=4.892$; $p<.05$.

Therefore, when the experimenter verbally described the context videos (Study 1), children in the patient-new condition expressed the patient more often in a lexical noun phrase than when the experimenter did not verbally describe the scenes (Study 2). That is, when the preceding context was only perceptually available, children dropped the new patient more often as opposed to in an additional discourse context.

\section{Discussion}

The main conclusion to be drawn from Study 2 is that whether or not the experimenter verbally described the context scenes prior to the question influenced children's answers with respect to the expression of the patient. Of interest, in Study 2 in almost half of the answers children dropped the patient in the patientnew condition despite the fact that it was new, whereas in Study 1 children hardly ever did so.

The question thus arises as to what role language plays in the context of Study 1. We know that when people listen to speech their visual attention matches the words they hear (Cooper, 1974). This is even true for 24-month-old children (Swingley, Pinto, \& Fernald, 1999). Further, a looking time study (Grassmann \& Tomasello, 2007) found that 24-month-olds look longer to the one element (out of two) that is both new in the visual context and stressed in the experimenter's verbal description. In a control condition, however, this study showed that visual newness alone (without any speech) has no effect. These findings by Grassmann and Tomasello might play an important role in our current study: in Study 1 the experimenter described the events in the video clips using natural stress, that is, slightly more stress fell on the patient. In the second scene, however, she stressed the new (and, thus, contrasting) element slightly more than the given element, that is to say, in the action-new condition the stress fell on the verb, whereas in the patient-new condition the stress fell on the patient. If we assume that, in our study, children also looked longer to the new and stressed element we could possibly conclude that this element is more salient to the child. In both conditions children's answers included a verb, possibly because of the predicate-focus question. Furthermore, because in the action-new condition the action is the new and stressed element, it might seem less relevant for the children to utter the patient. However, because in the patient-new condition the patient is the new and stressed element, children express it. 
In Study 2 no speech was used referring to the elements. Because (visual) newness alone did not cause increased looking time in Grassmann and Tomasello's (2007) study, it is possible that in our study the two elements of interest (action and patient) are equally salient to the child across conditions. In the actionnew condition, children performed in the same way as in Study 1. That is to say, they mainly responded with a single verb, possibly because both elements were equally salient but the question asked strongly for a verb phrase. In the patient-new condition, they answered most of the time with a verb and sometime additionally with a lexical noun, but about half of the children simply dropped the patient despite the fact that it was new. The reason for that might be that the new patient was less salient to them than in Study 1, because of the lack of language.

A slightly different explanation might be that the children used the verbal descriptions of the scenes as indicating the experimenter's interest in both elements, the action and the patient, because both were always named. Thus, when later on she asked what $\mathrm{X}$ was doing, children might think that the experimenter was not only interested in the action (as indicated by her question) but also that the patient is of importance to her. Therefore, when the patient is new, the children informed the experimenter of this; but when the patient was the same as the one the experimenter had just mentioned before, they simply omitted it. In Study 2 there was no verbal description to influence children in this way.

\section{GENERAL DISCUSSION}

This paper investigated 2-year-old children's answers to predicate-focus questions depending on the preceding context in which we manipulated the givenness/newness of either the action or the patient of that action. Although previous studies have exclusively focused on children's noun phrases in question answering, this is the first study that looked at children's verb phrases in that context.

We found that when the action was the new and contrasting element in a series of succeeding scenes, children were very likely to respond to the question with a one-word utterance, which was a single verb. However, when the patient was the new element, children used many more multiword utterances when answering the question: they expressed the patient typically as a lexical noun in their answers, and in addition, they included the verb very often, although less often than when the action was the new element. Thus, our findings suggest that children are very sensitive to both the predicate-focus question and newness as expressed in successively contrasting events.

Our results contribute to and extend previous findings on children's ability to encode new and given information. There is some early evidence that children show sensitivity to the flow of information in discourse. For instance, in a series of studies, Greenfield and colleagues (Baker \& Greenfield, 1988; Greenfield \& Smith, 1976; Greenfield \& Zukow, 1978) have shown that English-speaking children at the one-word stage verbalize the most informative element of the discourse situation. The verbalized element is usually the most variable aspect of the event 
Salomo et al.: Answering predicate-focus questions

and the one that reduces the uncertainty in the situation. Constant and redundant elements are those that are taken for granted and thus are left unexpressed. More recent studies with slightly older children have found that children pay attention to discourse pragmatics in choosing whether to represent an argument as a lexical noun or simply drop it (e.g., Allen, 2000; Clancy, 1997; Narasimhan et al., 2005; Serratrice, 2005). They showed that children produce lexical nouns more often when the argument they wish to represent is informative than when it is not. Indeed, this is our finding for the expression of the patient in the current study as well, that is to say, the patient was expressed as a full noun when it was new, but was simply omitted when it was given.

However, the case of question answering is in some sense different from that of other discourse contexts. A question sets up certain information expectations that must be realized in the information structure of the answer. That is to say, if the speaker is asking a predicate-focus question ("What is X doing?"), the addressee is expected to answer with a verb phrase, no matter whether the action is new or given information. Therefore, there are two factors that are relevant when answering questions in a given-new framework: (a) the focus of the question, and (b) newness in context. If children were only sensitive to the question, no difference between the two conditions would have been found. If they were sensitive to newness alone, the answers would have consisted of the new element only. However, because we found that children's answers included the new element as well as the verb in most cases, we can conclude that children at this early age are sensitive to both the question and newness, at least in a situation where the question is predicate focused and the contrasts in successive scenes make what is new and what given relatively accessible. The further finding, that even though children included a verb most often in their answers but did so more often in the action-new than in the patient-new condition, possibly results from the fact that the verb was the new element in the action-new condition while it was the given element in the patient-new condition.

Although previous studies have found that young children choose appropriate referring expressions for noun phrases when answering questions (Campbell et al., 2000; Matthews et al., 2006; Wittek \& Tomasello, 2005), we can now extend that finding to verb phrases as well. A further interesting finding was that children expressed new patients more often when there is a verbal discourse context prior to the questions (Study 1) than when there is not (Study 2). Because language directs our attention, it is possible that without any speech in the preceding context it is more difficult for young children to decide what is needed in an appropriate answer. Note that the verbal discourse provided the child with salient contrastive cues as to what is new.

One might further argue that children were primed by the verbal descriptions of the experimenter in Study 1 in which case they would be expected to produce more verb + patient answers. However, no difference was found in terms of multiword utterances (i.e., verb + patient answers) across studies. Furthermore, even with verbal descriptions (Study 1), children overwhelmingly produced one-word utterances in the action-new condition. This contradicts the assumption that the discourse context primed the children. Therefore, we can rule out the possibility 
of priming effects. An alternative explanation might be that in describing the context scenes, the experimenter naturally highlights the new information in the second context scene, which might make the new element more salient to the children.

However, there are limitations in our assumptions concerning children's production of verb phrases as answers to questions. We still do not know whether children would readily encode the action of an event without a question that focuses as strongly on a verb answer as does the predicate-focus question we used. It would be interesting to find how children reacted to a more neutral question, such as the one used by Matthews et al. (2006): What happened? Furthermore, because we used a different design than that of previous studies, we do not know how children would answer predicate-focus questions if the interlocutor was truly naive about the event about which the child is supposed to give information; that is, the interlocutor did not watch the film with the child. Therefore, further studies might apply a design in which something that is given for the child is new to the interlocutor. Finally, in Study 1, all the cues for the child were going in the same direction: visual, discourse, and contrast between successive scenes. In real life, this is unlikely to be the case and, as we see from Study 2, removal of the discourse context, seems to make it somewhat less clear to the child what the answer requires. A further study would be to repeat the study with scenes that are not so narrowly contrasted and see whether children perform equally well or whether they become more successful with development.

One strong suggestion emerging from the current study is that children at the age of 28 months are able to express verb phrases as answers to predicate-focus questions at least in this tightly contrastive situation. They seem to know that an answer referring to the action is required to that kind of question, no matter whether the action that is encoded by the verb is new or given. Furthermore, our results suggest that language supports children in establishing what is given and new information.

\section{APPENDIX A}

Overview of the four target scenes with their context scenes for both conditions

\begin{tabular}{cll}
\hline \hline & Action-New Condition & Patient-New Condition \\
\hline \multicolumn{3}{c}{ Target Scene 1 } \\
\hline $\begin{array}{l}\text { Context scene } \\
\text { (a) }\end{array}$ & $\begin{array}{l}\text { Frosch füttert Ente } \\
\text { (frog feeding duck) }\end{array}$ & $\begin{array}{l}\text { Frosch wäscht Käfer } \\
\text { (frog washing ladybug) }\end{array}$ \\
(b) & $\begin{array}{l}\text { Frosch kämmt Ente } \\
\text { (frog combing duck) }\end{array}$ & $\begin{array}{l}\text { Frosch wäscht Igel } \\
\text { (frog washing hedgehog) }\end{array}$ \\
Target scene & $\begin{array}{l}\text { Frosch wäscht Ente } \\
\text { (frog washing duck) }\end{array}$ & $\begin{array}{l}\text { Frosch wäscht } \text { Ente } \\
\text { (frog washing } \underline{\text { duck }} \text { ) }\end{array}$
\end{tabular}


Salomo et al.: Answering predicate-focus questions

Appendix A (cont.)

\begin{tabular}{cll}
\hline \hline & Action-New Condition & \multicolumn{1}{c}{ Patient-New Condition } \\
\hline \multicolumn{3}{c}{ Target Scene 2 } \\
\hline $\begin{array}{c}\text { Context scene } \\
\text { (a) }\end{array}$ & $\begin{array}{l}\text { Affe küsst Maus } \\
\text { (monkey kissing mouse) }\end{array}$ & $\begin{array}{l}\text { Affe schubst Kuh } \\
\text { (monkey pushing cow) }\end{array}$ \\
(b) & $\begin{array}{l}\text { Affe zieht Maus } \\
\text { (monkey pulling mouse) }\end{array}$ & $\begin{array}{l}\text { Affe schubst Pferd } \\
\text { (monkey pushing horse) }\end{array}$ \\
Target scene & $\begin{array}{l}\text { Affe schubst Maus } \\
\text { (monkey pushing mouse) }\end{array}$ & $\begin{array}{l}\text { Affe schubst Maus } \\
\text { (monkey pushing } \underline{\text { mouse }} \text { ) }\end{array}$ \\
\hline
\end{tabular}

Target Scene 3

\begin{tabular}{cll}
\hline $\begin{array}{l}\text { Context scene } \\
\text { (a) }\end{array}$ & $\begin{array}{l}\text { Frosch füttert Teddy } \\
\text { (frog feeding teddy) }\end{array}$ & $\begin{array}{l}\text { Frosch haut Pferd } \\
\text { (frog hitting }\end{array}$ \\
(b) & $\begin{array}{l}\text { Frosch kämmt Teddy } \\
\text { (frog combing teddy) }\end{array}$ & $\begin{array}{l}\text { Frosch haut } \\
\text { (frog hitting }\end{array}$ \\
Target scene & $\begin{array}{l}\text { Frosch haut Teddy } \\
\text { (frog hitting teddy) }\end{array}$ & $\begin{array}{l}\text { Frosch haut } \\
\text { (frog hitting }\end{array}$ \\
\hline
\end{tabular}

Target Scene 4

\begin{tabular}{|c|c|c|}
\hline \\
\hline $\begin{array}{l}\text { Context scene } \\
\text { (a) }\end{array}$ & $\begin{array}{l}\text { Affe küsst Löwe } \\
\text { (monkey kissing lion) }\end{array}$ & $\begin{array}{l}\text { Affe streichelt Schaf } \\
\text { (monkey stroking sheep) }\end{array}$ \\
\hline (b) & $\begin{array}{l}\text { Affe zieht Löwe } \\
\text { (monkey pulling lion) }\end{array}$ & $\begin{array}{l}\text { Affe streichelt Igel } \\
\text { (monkey stroking hedgehog) }\end{array}$ \\
\hline Target scene & $\begin{array}{l}\text { Affe streichelt Löwe } \\
\text { (monkey stroking lion) }\end{array}$ & $\begin{array}{l}\text { Affe streichelt Löwe } \\
\text { (monkey stroking lion) }\end{array}$ \\
\hline
\end{tabular}

Note: The new elements are underscored.

\section{ACKNOWLEDGMENTS}

We are grateful to the Leipzig kindergarten directors and children who participated in the studies. We thank Eileen Graf and Jana Jurkat for help in creating the stimuli, Roger Mundry for statistical guidance, and Susanne Grassmann for helpful comments on the manuscript.

\section{NOTES}

1. Apart from real verbs, childhood language words referring to actions such as ei machen $($ ahl doing $)=$ to stroke, aua machen $($ ow doing $)=$ to hit/ to hurt, bums machen $($ bump doing) $=$ to fall over $)$ were counted as actions as well.

2. The agent was dropped most of the time $(75.0 \%)$, was in some cases pronominalized $(18.3 \%)$ and rarely expressed as lexical noun phrase $(6.7 \%)$. There was no difference between the two conditions. 
Salomo et al.: Answering predicate-focus questions

3. For each of these statistical analyses as well as for every further analyses reported below, there was a significant main effect for Condition (with $p$ values ranging from $<.001$ to $<.05)$.

\section{REFERENCES}

Allen, S. E. M. (2000). A discourse-pragmatic explanation for argument representation in child Inuktitut. Linguistics, 38, 483-521.

Baker, N. D., \& Greenfield, P. M. (1988). The development of new and old information in young children's early language. Language Sciences, 10, 3-34.

Cameron-Faulkner, T., Lieven, E., \& Tomasello, M. (2003). A construction based analysis of child directed speech. Cognitive Science, 27, 843-873.

Campbell, A. L., Brooks, P., \& Tomasello, M. (2000). Factors affecting young children's use of pronouns as referring expressions. Journal of Speech, Language, and Hearing Research, 43, $1337-1349$.

Chafe, W. L. (1976). Givenness, contrastiveness, definiteness, subjects, topics, and point of view. In C. N. Li (Ed.), Subject and topic (pp. 25-55). New York: Academic Press.

Clancy, P. M. (1997). Discourse motivations of referential choice in Korean Acquisition. In H. Sohn \& J. Haig (Eds.), Japanese/Korean linguistics (Vol. 6, pp. 639-659). Stanford, CA: Center for the Study of Language and Information.

Cooper, R. M. (1974). The control of eye fixation by the meaning of spoken language. Cognitive Psychology, 6, 84-107.

Ervin-Tripp, S. (1970). Discourse agreement: How children answer questions. In J. R. Hayes (Ed.), Cognition and the development of language. New York: Wiley.

Gentner, D. (1982). Why nouns are learned before verbs: Linguistic relativity versus natural partitioning. In S. Kuczaj (Ed.), Language development (Vol. 2). Hillsdale, NJ: Erlbaum.

Grassmann, S., \& Tomasello, M. (2007). The effect of focal stress on two-year-olds' visual attention. Poster presented at the Child Language Seminar.

Greenfield, P. M., \& Smith, J. (1976). The structure of communication in early language development. New York: Academic Press.

Greenfield, P. M., \& Zukow, P. G. (1978). Why do children say what they say when they say it? An experimental approach to the psychogenesis of presupposition. In K. Nelson (Ed.), Children's language (Vol. 1). New York: Gardner Press.

Kiefer, F. (1988). On the pragmatics of anwers. In M. Meyer (Ed.), Questions and questioning. New York: De Gruyter.

Lambrecht, K. (1994). Informatione structure and sentence form: Topic, focus and the mental representation of discourse referents. New York: Cambridge University Press.

Matthews, D., Lieven, E., Theakston, A., \& Tomasello, M. (2006). The effect of perceptual availability and prior discourse on young children's use of referring expressions. Applied Psycholinguistics, $27,403-422$.

Narasimhan, B., Budwig, N., \& Murty, L. (2005). Argument realization in Hindi caregiver-child discourse. Journal of Pragmatics, 37, 461-495.

Peterson, C., \& Biggs, M. (1997). Interviewing children about trauma: Problems with "specific" questions. Journal of Traumatic Stress, 10, 279-290.

Salomo, D., Lieven, E., \& Tomasello, M. (2009). Young children's ability to answer different types of question. Manuscript submitted for publication.

Serratrice, L. (2005). The role of discourse pragmatics in the acquisition of subjects in Italian. Applied Psycholinguistics, 26, 437-462.

Swingley, D., Pinto, J. P., \& Fernald, A. (1999). Continuous processing in word recognition at 24 months. Cognition, 71, 73-108.

Tyack, D., \& Ingram, D. (1977). Children's production and comprehension of questions. Journal of Child Language, 4, 211-224.

Wittek, A., \& Tomasello, M. (2005). Young children's sensitivity to listener knowledge and perceptual context in choosing referring expressions. Applied Psycholinguistics, 26, 541-558. 